\title{
La mala obstetrix y la buena matrona. Estereotipos femeninos en la medicina medieval
}

\section{The evil midwife and the good matron. Female stereotypes in medieval medicine}

\author{
PALOMA MORAL DE CALATRAVA \\ Universidad de Murcia \\ pmoral@um.es
}

\begin{abstract}
Resumen: En la Edad Media hubo diferentes calificativos para denominar a las mujeres que cuidaron la salud de otras mujeres. En latín utilizaron matrona y obstetrix, mientras que las lenguas vernáculas pudieron utilizar muchos otros términos. Este trabajo analiza la influencia de la estereotipación de las mujeres en la creación de un continuum semántico que ocultaba las competencias médicas femeninas. Mientras que la sucia y deshonesta tarea terapéutica de provocar un orgasmo a la paciente fue sistemáticamente asignada a las "obstetrices" y parteras, utilizaron términos diferentes para identificar a aquellas que inspeccionaban a las mujeres cerradas. Si las parteras aparecen en problemas ginecológicos, dado que la estrechez podía implicar el divorcio, la Iglesia encargó a un grupo de mujeres que examinara los genitales femeninos. El estudio diacrónico de los diversos términos con los que fueron denominadas esas mujeres muestra que la moral cristina fue el criterio que utilizaron los hombres para clasificar a esas mujeres.
\end{abstract}

Palabras clave: Partera, matrona, estereotipos, moral cristiana, medicina.

\begin{abstract}
In the Middle Ages, there were different labels to identify those women who took care of other women's health. 'Matron' and 'obstetrix' were used in Latin, meanwhile vernacular languages could use a lot of terms. This paper analyzes how long the ideology about female moral was present in the creation of a semantic continuum which overshadowed women's medical competencies. The therapeutic, but dirty and dishonest task to cause to the patient an orgasm was systematically assigned to the 'obstetrices' along the ancient and medieval manuscripts, whereas the diagnosis and surgical procedure related with the 'clausio matricis' was more problematic. Because this narrow condition could imply a divorce, Church commanded to a group of women to examine the female pudenda. The diachronic study of diverse terms which those women were named show that the Christian moral was the criteria men used to classify those women.
\end{abstract}

Keywords: Midwife, matron, stereotypes, Christian moral, medicine.

Recibido: 12 de febrero de 2018; aceptado: 20 de julio de 2018; publicado: 27 de septiembre de 2018.

Revista Historia Autónoma, 13 (2018), pp. 15-29

DOI: https://doi.org/10.15366/rha2018.13.001 
"Y esta comunmente en lengua Castellana es llamada comadre o partera.

En lengua Catalana se dize madrina. En latin es llamada Obstetrix, quiere dezir quasi obstatriz contra parturientes compone se ex ob et estera, scilicet: obstetrix obstetricis que propiamente es la muger que trata la extera que es el panniculo enel qual la criatura esta embuelta enel vientre de su madre. Aun que se corrompe el vocablo"1.

Aunque el médico mallorquín Damián Carbón afirmara en 1541 que las voces vernáculas "partera", "madrina" o "comadre" eran sinónimas al término latino de obstetrix, lo cierto es que tan solo la palabra "partera" tuvo un significado preciso ligado a la práctica médica, mientras que el resto eran vocablos polisémicos que pudieron emplearse en contextos distintos; de ahí su corrupción. Cabría esperar que los textos médicos redactados en latín fueran consistentes e identificaran siempre como obstetrix a aquella mujer que ayudaba a otra durante sus problemas obstétricos y enfermedades ginecológicas, pero una lectura detallada de los textos revela que también la llamaron matrona. ¿Por qué tanto los libros médicos escritos en latín como las fuentes vernáculas identificaron con nombres distintos a las mujeres que atendían la salud femenina?

Los posicionamientos historiográficos sobre la actividad y calificativos de estas mujeres son diversos. Una parte de la investigación afirma que, en la vida diaria, la obstetricia y la ginecología fueron prácticas exclusivamente femeninas, por lo que asume que en la Baja Edad Media también existió la equivalencia terminológica que Carbón apuntó para el siglo $\mathrm{XVI}^{2}$. Otra corriente subraya que las palabras hacían referencia a mujeres con saberes distintos, y considera que ocurría tanto en los textos escritos en latín como los elaborados en lenguas vernáculas. Según esta postura, cuando en un texto aparecen las voces obstetrix o partera se están refiriendo a una mujer con conocimientos médicos, pero cuando utilizaban las palabras matrona, comadre o madrina se estaban refiriendo a unas mujeres que no sabían de medicina ${ }^{3}$.

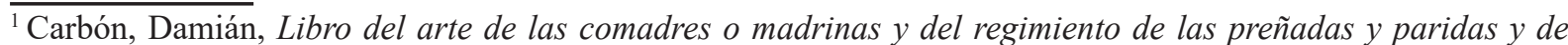
los niños, Mallorca, Hernando de Cansoles, 1541. Editado por Alejandra Piñeyrúa en Herrera, Teresa y María Estela González de Fauve (dirs.), Textos y Concordancias electrónicos del Corpus Médico Español, Madison, The Hispanic seminal of Medieval Studies, 1997, fol. 7r.

${ }^{2}$ Wynne Johnson, Rebecca, "Divisions of Labor: Gender, Power, and Later Medieval Childbirth, c. 1200-1500", en History Compass, vol. 14, 9 (2016), pp. 383-396, esp. pp. 383-384. DOI: https://doi.org/10.1111/hic3.12335. Aportaciones españolas en este sentido son, por ejemplo, García Herrero, María del Carmen, "«Administrar el parto y recibir a la criatura». Aportación al estudio de la Obstetricia Bajomedieval", en Aragón en la Edad Media, 8 (1989), pp. 283-292 [reimp. en García Herrero, María del Carmen, Del nacer y del vivir. Fragmentos para una historia de la vida en la Baja Edad Media, Zaragoza, Institución Fernando el Católico y Consejo Superior de Investigaciones Científicas, 2005, pp. 21-46]; González Hernando, Irene, "La figuración de la ciencia. Espacios y objetos de parto en el arte medieval español”, en Goya, 342 (2013), pp. 3-17: González Hernando, Irene , "Posiciones fetales, aborto cesárea e infanticidio. Un acercamiento a la Ginecología y la Puericultura hispánica a través de tres manuscritos medievales", en Miscelánea Medieval Murciana, 39 (2009), pp. 99-122; García Martínez, Manuel Jesús, "El oficio de la partera entre los siglos xv al xviii. Fuentes documentales para su estudio", en Cultura de los cuidados, 32 (2012), pp. 88-95; García Martínez, Manuel Jesús, "Prácticas ancestrales de las matronas españolas: el «agua de socorro» o bautismo de urgencia. Fuentes para su estudio", en Híades. Revista de Historia de la Enfermería, 11 (2015), pp. 321-344; Molina García, Leticia et al., "Recorrido histórico de la profesión de matrona: una revisión bibliográfica", en Revista Paraninfo digital, 25 (2016). «http://www.index-f. com/para/n25/335.php» [consultado el 23 de septiembre de 2017].

${ }^{3}$ Green, Monica, "Documenting Medieval Women's Medical Practice", en García-Ballester, Luis et al. (eds.) Practical medicine from Salerno to the Black Death, Cambridge, Cambridge University Press, 1994 [reimp., en Green, Monica, Women's Healthcare in the Medieval West: Texts and Contexts, Aldershot, Ashgate, 2000]; Green,
} 
Esta postura historiográfica sostiene, además, que el número de parteras en la Edad Media fue residual porque carecieron de tratados específicos para su educación médica y no se organizaron en gremios. Un tercer posicionamiento sostiene que los diversos vocablos utilizados en las lenguas vernáculas estuvieron relacionados con el dominio semántico y simbólico de las palabras "mujer" y "madre". Los términos comadre y madrina ilustran esa relación alegórica, un vínculo propio del lenguaje de las mujeres, ya que estas empleaban la lengua materna y no utilizaban una terminología médica técnica ${ }^{4}$. Esta tendencia reconoce que no todas las mujeres que atendieron la salud femenina tuvieron los mismos conocimientos, y comprende que partera, matrona, comadre o madrina fueron palabras insertadas en un continuum semántico de significación diferente al del lenguaje científico masculino.

Todas estas corrientes coinciden en afirmar, sin embargo, que la obstetricia fue un campo practicado en su mayoría por las mujeres: lo que se pone en duda es la presencia de las parteras en el diagnóstico y tratamiento de las enfermedades femeninas. Este trabajo explora los términos que se emplearon en dos problemas ginecológicos para demostrar que el continuum semántico que propone esta última corriente historiográfica era una gradación moral, de modo que desde el siglo XIII los términos obstetrix y partera fueron etiquetas con un significado médico aparente. Es decir, mientras que la voz matrona identificaba a una mujer con una fama pública de honesta, decente e íntegra, las palabras obstetrix y partera hacían referencia a mujeres de moral incierta. Para demostrar que la honestidad femenina fue el criterio que utilizaron los médicos para reconocer a una mujer como una obstetrix o como una matrona, en este trabajo analizo de forma diacrónica dos enfermedades ginecológicas relacionadas con las relaciones sexuales: la sofocación uterina y la clausio matricis. Ya que las tres corrientes afirman que las parturientas fueron atendidas mayoritariamente por otras mujeres, este trabajo estudia dos problemas de salud que no estaban relacionados con el parto y demuestra que el placer sexual asociado al tratamiento marcó el devenir de cada una de ellas. Uno de los procedimientos para curar la sofocación uterina fue un masaje genital que provocaba el orgasmo; los tratados médicos medievales identificaron sistemáticamente como obstetrix o partera a la mujer que debía ejecutarlo. De otra parte, las fuentes escritas en latín reconocieron como matronas al grupo de mujeres que inspeccionaban el cuerpo femenino para diagnosticar la clausio matricis, una anomalía genital que impedía las relaciones sexuales y podía implicar la nulidad matrimonial. La Iglesia estableció que un grupo de matronas realizara un examen físico y no utilizó el término obstetrix porque consideró que estas mujeres no eran las personas adecuadas para la exploración ginecológica. Como demostraré, la ideología cristiana sobre el placer erótico y la

\footnotetext{
Monica, "Caring for Gendered Bodies" en Bennett, Judith M. y Ruth Mazo Karras, The Oxford Handbook of Women and Gender in Medieval Europe, Oxford, Oxford University Press, 2013, pp. 345-361, esp. p. 348.

${ }^{4}$ Cabré i Pairet, Montserrat, "Women or Healers? Household Practices and the Categories of Health Care in Late Medieval Iberia", en Bulletin of the History of Medicine, 82 (2008), pp. 183-195; Cabré i Pairet, Montserrat, "Nacer en relación", en Cabré i Pairet, Montserrat et al., De dos en dos. Las prácticas de creación y recreación de la vida y la convivencia humana, Madrid, Horas y Horas, 2000, pp. 15-32.
} 
necesidad de acentuar el carácter moral de la mujer que atendía a otra motivó que sustituyeran las voces obstetrix o partera por otras menos concretas, como matrona, comadre o madrina; unos términos que no denotaban competencia científica o profesional. Todas estas palabras guardaron entre sí sinonimia referencial y el remplazo de unos términos por otros no fue inocente, porque ocultaron las habilidades clínicas de estas mujeres para resaltar sus características morales.

\section{La sofocación uterina y el masaje inmoral}

En la medicina griega clásica la sofocación uterina ya era una patología antigua causada por el ascenso del útero que comprimía diferentes órganos. La enfermedad se presentaba de forma rápida $\mathrm{y}$, entre otros síntomas, originaba el movimiento descontrolado de los ojos, el rechinar de los dientes, la expulsión de abundante saliva, impedía la respiración y paraba el pulso; era una enfermedad que, en definitiva, amenazaba la vida de la mujer ${ }^{5}$. Los médicos hipocráticos relacionaron este trastorno con la falta de relaciones sexuales y afirmaron que, como el semen masculino no humedecía al útero, este perdía su complexión y ascendía hacia el corazón, los hipocondrios o el hígado. Para revertir el desplazamiento uterino trataban a las enfermas con fumigaciones nasales y vaginales, pesarios y purgas, pero las relaciones sexuales y el embarazo fueron el remedio por excelencia ${ }^{6}$.

Si la medicina hipocrática afirmó que la sofocación era consecuencia de la falta de esperma masculino, Galeno sostuvo que la causa era la acumulación del "semen femenino"7. Para el médico romano, las mujeres que no mantenían relaciones heterosexuales periódicas no disfrutaban del placer erótico de la fricción genital, un mecanismo que consideró imprescindible para que las mujeres expelieran su propia semilla ${ }^{8}$. Pese a que las teorías hipocrática y galénica sobre la sofocación uterina compartieron algunos supuestos, las diferencias fueron notables: ambas corrientes vincularon la enfermedad con la falta de relaciones sexuales, una y otra aceptaron el listado de síntomas, las dos corroboraron que el coito regular era la primera medida higiénica y los tratamientos farmacológicos alternativos al sexo fueron los mismos. Pero Galeno afirmaba que las mujeres no eran meros receptáculos del semen masculino, que ellas también producían una simiente que debía expulsarse mediante el orgasmo y, en consecuencia, consideró

\footnotetext{
${ }^{5}$ Mul. I, 1, 7. Traducido por Sanz Mongote, Lourdes y José Antonio Ochoa Anandón, Tratados hipocráticos, Madrid, Gredos, 1988, pp. 59-60.

${ }^{6}$ Mul. II, 127. Sanz Mongote, Lourdes y José Antonio Ochoa Anandón, Tratados hipocráticos... op. cit., pp. 220221.

${ }^{7}$ Para Galeno, la continencia era peligrosa para la salud de hombres y mujeres, y llegó a la conclusión de que la emisión seminal era un acto tan natural como la expulsión de heces u orina. Galeno, Sobre los lugares afectados, Madrid, Gredos, 2000, p. 377. 8.

${ }^{8}$ Galeno, Sobre el semen, Madrid, Ediciones Clásicas, 2016, pp. 175-176 y 179.
} 
que el masaje genital era un tratamiento adecuado ${ }^{9}$. El médico romano sostenía que hombres y mujeres necesitaban eliminar el exceso de esperma y para demostrar su teoría introdujo un caso. Mientras estaba reflexionando sobre un paciente viudo que se había curado al recuperar la costumbre de mantener relaciones sexuales frecuentes, ocurrió lo siguiente:

"Estando yo una vez reflexionando sobre esto se me presentó un caso parecido
con una mujer viuda desde hacía mucho tiempo. Estaba presa entre otras
molestias de distensiones de los nervios; me dijo la partera que la matriz estaba
retraída y le prescribí los remedios a los que es costumbre recurrir en semejantes
casos. Cuando hizo uso de ellos, en parte por el calor que producen y porque
para su aplicación rozaban los órganos genitales femeninos, le sobrevinieron
contracciones acompañadas a la vez de dolor y de placer, parecidas a las que
ocurren en las relaciones sexuales, después de las cuales se expulsa un esperma
espeso y abundante; la mujer se vio libre de las molestias que la aquejaban"lo.

Una lectura rápida del caso de la viuda de Galeno podría llevarnos a conclusiones precipitadas; de hecho, más bien parece un caso creado ad hoc para demostrar que las parteras seguían una teoría que él consideraba desfasada ${ }^{11}$. El pasaje no deja claro si la enferma era paciente de esta mujer y ella consultó con el médico, o si la aquejada fue directamente a Galeno y este, en vez de inspeccionar el útero de primera mano, recurrió a la partera para la inspección física. En cualquier caso, fue ella quien realizó la exploración y diagnosticó la sofocación siguiendo la teoría hipocrática del ascenso uterino por falta de relaciones sexuales. Podría pensarse que la medicina hipocrática recogió por escrito la actividad médica de las mujeres y que las parteras tenían un papel importante en las enfermedades femeninas, pero lo cierto es que, en el Corpus hipocrático, las mujeres tan solo aparecen dos veces y en una de ellas no está claro si se referían a una mujer que sabía medicina ${ }^{12}$. Es más, ninguno de los dos casos está relacionado con la sofocación uterina, de modo que, aunque la medicina hipocrática prescribiera el matrimonio para curar a las pacientes, las mujeres utilizaron la masturbación como remedio incluso antes de que Galeno confirmara su eficacia. El médico romano recomendó los remedios habituales que se aplicaban en los genitales, pero no dijo haberlo hecho él mismo, por lo que algunos piensan que el médico no vio en ningún momento a la paciente y que únicamente conocía el caso de

\footnotetext{
${ }^{9}$ Los textos ginecológicos hipocráticos solo recogieron los tratamientos farmacológicos: Mul. II, 123; Mul. II, 124; Mul. II, 125; Mul. II, 127; y Mul. II, 128. Sanz Mongote, Lourdes y José Antonio Ochoa Anandón, Tratados hipocráticos... op. cit. En Mul. I, 32 tan solo se advierte de que las mujeres embarazadas también pueden sufrir sofocaciones porque el feto podía ascender. Para la teoría de la sofocación hipocrática cfr. King, Helen, Hippocrates' Woman. Reading the Female Body in Ancient Greece, Londres y Nueva York, Routledge, 1998, esp. pp. 205-222. Para los instrumentos médicos que podían utilizarse en la terapia farmacológica $c f r$. Bliquez, Lawrence J., The Tools of Asclepius. Surgical Instruments in Greek and Roman Times, Leiden y Boston, Brill, 2015, esp. pp. 45-47, 69-71, 211-212, 229-230 y 295.

${ }^{10}$ Galeno, Sobre los lugares afectados... op. cit., p. 380.

${ }^{11}$ Ibídem, p. 386; King, Helen, "Galen and the Widow. Towards a History of Therapeutic Masturbation in Ancient Gynaecology”, en Eugesta, 1 (2011), p. 222.

${ }^{12}$ En los tratados hipocráticos la partera solo aparece dos veces. En Mul. I, 68, extrayendo un feto muerto, y en Mul. I, 21, tan solo se recomienda que "otra mujer" inspeccione el útero para determinar si está liso y no rugoso, sin asignarle ninguna etiqueta relacionada con la atención sanitaria.
} 
forma indirecta ${ }^{13}$. Un último aspecto a considerar: podría parecer que fue la partera quien aplicó el medicamento, pero Galeno solo afirmó que la terapia funcionó por el calor que provocaban las medicinas y el masaje, y no aclaró si fue la propia enferma quien friccionó el ungüento.

Galeno incluyó este caso para demostrar la importancia de la emisión seminal femenina y, aunque no especificó quién hizo el masaje, el papel de las parteras no era el de meras ejecutoras de órdenes médicas, sino que debían realizar la inspección y formular el diagnóstico. Pero un médico de Justiniano llamado Aecio de Amida ofreció en el siglo vi una visión diferente sobre las tareas de las obstetrices. En el capítulo que dedicó a la apnea uterina, el médico bizantino se basó en Galeno y también incluyó un caso, pero en su historia la enferma perdió la conciencia y fue la partera quien masajeó los genitales hasta que la paciente expulsó el semen nocivo y volvió en sí $^{14}$. Las diferencias entre la partera de Galeno y la de Aecio son sustanciales porque si la del médico romano exploraba a la paciente y determinaba la patología, el cometido de la partera de Aecio se restringió a ejecutar el procedimiento, lo que demuestra que la práctica médica femenina ya estaba subordinada.

En la medicina antigua hubo una tercera escuela sobre cómo tratar a las mujeres sofocadas que negaba los beneficios de las relaciones sexuales, abanderada por uno de los médicos más importantes para la ginecología antigua: Sorano de Éfeso. Poco antes de Galeno, el médico metodista negó que la sofocación se debiera a la falta de contacto erótico, por lo que cualquier remedio sexual carecía de sentido, ya fuera el coito, la masturbación o el masaje de la partera. La Edad Media conoció la teoría de Sorano gracias a tres traducciones, pero la más influyente fue la que hizo un tal Muscio en el norte de África en el siglo vi. Muscio, sin embargo, cambió el original e introdujo una contradicción flagrante: de una parte, no respetó el texto de Sorano y afirmó que la abstinencia desencadenaba la enfermedad y, de otro lado, sostenía que las terapias sexuales eran perjudiciales ${ }^{15}$.

La Edad Media, por lo tanto, heredó tres corrientes de pensamiento respecto al tratamiento erótico: la tradición hipocrática recomendaba el coito matrimonial y no incluía a la partera; la teoría galénica aconsejaba la expulsión de la semilla femenina, por lo que las relaciones sexuales, la masturbación o el masaje de la obstetrix eran tratamientos idóneos; mientras que la soránica rechazaba cualquiera de estos remedios. Aunque los enfoques de las diferentes escuelas parezcan incompatibles, la medicina medieval recibió una visión bastante homogénea sobre la patología, pues las causas, la sintomatología, la población vulnerable y los remedios farmacológicos distintos al sexo fueron elementos compartidos. Las fuentes europeas

\footnotetext{
${ }^{13}$ King, Helen, "Galen and the Widow..." op. cit., p. 222, n. 98.

${ }^{14}$ Aetios of Amida, The Gynaecology and Obstetrics of the VIth Century, Philadelphia y Toronto, The Blakiston Company, 1950, esp. pp. 70-74; King, Helen, Hippocrates' Woman... op. cit., esp. p. 234; Gilman, Sander et al., Hysteria Beyond Freud, Berkeley, Universidad de California, 1993, p. 46.

${ }^{15}$ Bolton, Lesley Annette, An Edition, Translation and Commentary of Mustio's Gynaecia, tesis doctoral, Universidad de Calgary, 2015, esp. pp. 137-139. Existe una edición al italiano anterior: Muscio, Gynaecia, Pisa, Giardini, 1970, esp. pp. 48 y 50; Hanson, Ann Ellis y Monica Green, "Soranus of Efesus: Methodicurum Princeps", en Haase, Wolfganag y Hildegard Temporini (eds.), Rise and Decline of the Roman Word, Berlín y Nueva York, De Gruyter, 1994, pp. 968-1075, esp. pp. 1051-1052.
} 
reintrodujeron el tratamiento erótico en el siglo XII, lo que no significa que antes desconocieran la importancia de la friega genital, sino que prefirieron silenciarlo. Por ejemplo, el benedictino Constantino el Africano tradujo en el siglo XI dos importantes obras de dos médicos musulmanes que habían aconsejado abiertamente tanto el masaje de las parteras como el coito matrimonial ${ }^{16}$, pero en la versión latina del monje solo aparecen indicaciones sucintas sobre la necesidad de ungir con aceites olorosos el interior y el exterior de la vulva omitiendo quién debía ejecutarlo y la importancia de frotar el sexo hasta que la enferma expulsara su semilla ${ }^{17}$.

Aunque Constantino había eliminado en sus traducciones el placer concomitante a la terapia, no fue el único que conocía el contenido de las fuentes árabes y, a partir del siglo XII, los médicos salernitanos comenzaron a tenerlas en cuenta. Por eso, además de los tratamientos farmacológicos, Johannes Platearius (ca. 1150) y Johannes de Sancto Paulo (1181) recomendaron el coito matrimonial y que las doncellas, viudas y monjas se masturbaran; sin embargo, ninguno consideró a la obstetrix como una opción terapéutica ${ }^{18}$. Hasta el siglo XI, pese a saber que el orgasmo formaba parte de la cura, las traducciones latinas ocultaron deliberadamente la función curativa del placer sexual, aunque a partir del XII se reintrodujeron algunas prácticas eróticas recomendadas en los tratados antiguos ${ }^{19}$. Solo cuando el Canon de Avicena fue un texto de lectura obligada en las facultades de medicina del siglo xIII, la Europa cristiana comenzó a considerar el masaje de la partera como una opción terapéutica porque podían leer lo siguiente:

\footnotetext{
$\overline{{ }^{16} \text { Gilman, Sander }}$ et al., Hysteria Beyond Freud... op. cit., p. 52.

${ }^{17}$ En el Pantegni tan solo aparece lo siguiente; "[...] in inguine vngamus vulvam cum oleis odoriferis interius et exterius", y en el Viaticum una frase parecida: "vngamus os vulve cum oleis odoriferis intrinsecus et extrinsecus". Tomado de Green, Monica, The Transmission of Ancient Theories of Female Physiology and Disease Through the Early Middle Ages, tesis doctoral, Universidad de Princeton, 1985, pp. 248-249, n. 76; Moral de Calatrava, Paloma, "Sexo, salud y sacramento. Las relaciones sexuales y la salud de las mujeres en la Edad Media", en Arenal, vol. 16, 2 (2009), pp. 235-262, esp. p. 256; Green, Monica, "The Re-Creation of Pantegni Practica VIII", en Burnett, Charles y Danielle Jacquart (eds.), Constantine the African and 'Alī Ibn Al-'Abbās Al-Mă̌ūsī. The Pantegni and Related Text, Lieden, Nueva York y Colonia, Brill, 1994, pp. 121-160, esp. pp. 129-131 y 137-138. ${ }_{18}$ Plateario aconsejó un remedio farmacológico alternativo a las mujeres que no podían mantener relaciones sexuales, y no sugirió el masaje de la obstetrix: "Si ex corrupto spermate fiat, si virum habeat. Si virgo es vel viuda consilium ... ut nubat, si voto castitatis vel continentie teneatur, fiat hoc remedium, salgemma, nitrum pulverizantur et distemperentur cum aceto et aqua salsa, et bombix incticta imponatur, ex hoc enim fit quedam morditio unde [...]". "De aegritudinum curatione", en de Renzi, Salvatore (ed.), Collectio Salernitana, vol. 2, Nápoles, Dalla tipografia del Filiatre-Sebezio, 1853, p. 339. Cfr. Green, Monica, The Transmission of Ancient... op. cit., p. 267. Victoria Recio, sin embargo, asegura que Plateario afirmó que si los fármacos no funcionaban, las monjas podían masturbarse. Cfr. Recio, Victoria, "Passiones mulierum. Mujer y enfermedad en la Escuela médica de Salerno", en de la Rosa Cubo, Cristina et al., Trabajo, creación y mentalidades de las mujeres a través de la Historia, Valladolid, Universidad de Valladolid, 2001, pp. 127-143, esp. pp. 136-137. Sancto Paulo aconsejó a las viudas la masturbación y a las doncellas el uso de un artefacto similar al miembro viril, aunque parece que no se detuvo en el caso de las monjas: "Vidua: immittat sibi manum et alleuiabitur. Pro uirgine autem fiat aliquod molle simile membro uirili de nitro et cera et nasturtio. Diligentur trita et subiciatur donec pati poterunt". Tomado de Green, Monica, Making Masculine... op. cit., p. 44, n. 41. Para la traducción manuscrita de Sancto Paulo cfr. Martín Ferreira, Ana Isabel, "Génesis, estructura y pervivencia de un compendio médico salernitano: el Breviarium de Johannes de Sancto Paulo", en Muñoz, María José et al. (eds.) La compilación del saber en la Edad Media, Oporto, Fédération Internationale des Instituts d'Études Médiévales, 2013, pp. 367-381, esp. p. 379, n. 28. DOI: https://doi.org/10.1484/M.TEMA-EB.4.01062. Aunque parece que la influencia de Sancto Paulo fue limitada, se han identificado 35 manuscritos. Cfr. Martín Ferreira, Ana Isabel y Alejandro García González, "La tradición manuscrita del Breviarium de Johannes de Sancto Paulo", en Exemplaria Classica, 14 (2010), pp. 227-248.

${ }^{19}$ Green ya destacó que Constantino no fue consistente respecto a los beneficios del sexo regular, y si lo recomendó en otras partes del Pantegni lo eliminó del capítulo dedicado a la sofocación. Cfr. Green, Monica, "Constantinus Africanus and the Conflict Between Religion and Science", en Dunstan, Gordon R. (ed.), The Human Embryo: Aristotle and the Arabic and European Traditions, Exeter, Exeter University Press, 1990, pp. 47-69, esp. pp. 56-57 y 66, n. 43.
} 
"Et opportet vt intromittat obstetrix manus suas in vulvam eius intinctas oleo de lilio: aut nardino: aut laurino: et commoueat portam vulue et portam matricis motione plurima leui. Et necessarium est vt associetur ei cum delectatione dolor et fit sicut est dispositione coitus" ${ }^{20}$.

El masaje genital para la sofocación uterina entrañaba problemas morales al inducir al orgasmo, y médicos y cirujanos evitaron hacer ellos mismos la friega. En el siglo XIII, al tiempo que la medicina asumía los beneficios salutíferos de las relaciones sexuales, se desarrolló una etiqueta médica que aconsejaba a los galenos que guardaran castidad tanto con sus pacientes como con la esposa del enfermo ${ }^{21}$. El requisito de que la afectada tuviera que experimentar placer para curarse fue un factor decisivo para que los hombres dejaran en manos de parteras el masaje. A partir del siglo XIII, sin embargo, algunos autores defendieron que los cirujanos vieran, tocaran e intervinieran los genitales femeninos, pero de ninguna manera esos procedimientos exigían que las mujeres experimentaran placer. Por ejemplo, Alberto Magno consideró necesario que los cirujanos tocaran la matriz cuando salía al exterior y advirtió que no todas las manipulaciones sobre los genitales tenían intención erótica ${ }^{22}$. Los cirujanos Guillermo de Saliceto (XIII) y Guy de Chauliac (XIV) tenían la misma opinión, y sostuvieron que los hombres podían operar a las mujeres con piedras en la vejiga - una intervención en la que era necesario que introdujeran los dedos en el ano o vagina para localizar el cálculo- ${ }^{23}$. Por lo tanto, a la hora de identificar quién debía ejecutar un procedimiento influyó más que el placer fuera el remedio, que el hecho de que un hombre viera, tocara e interviniera los genitales de una paciente.

Aunque el masaje genital fuera el último recurso, se aconsejaba una técnica corporalmente sucia y moralmente indecente que exponía a dos mujeres a un procedimiento rayano en el peligroso contacto homoerótico. El carácter deshonesto de la técnica explica por qué algunas

\footnotetext{
20 "Y la partera debe introducir su mano en su vulva [la de la enferma] untada en aceite de lirio, o de nardo, o de laurel y agitar la entrada de la vulva y la de la matriz con movimientos muy rápidos. Y es necesario que estos [movimientos] sean como los que suceden durante el coito con placentero dolor". Avicenna, Liber Canonis, Venecia, 1507, Liber III, fen, XXI, tract. IIII, cap. XVIII De cura, fol. 337a. La traducción y el énfasis son míos. ${ }^{21}$ Lanfranco de Milán (XIII) censuró que los cirujanos se comportaran de la siguiente manera: "Non sea gosloso, njn fornjcador njn embidioso njn auariento. Sea fiel et assi se ofrezca todo al enfermo que cosa alguna de las conteçientes non sea dexada de su parte. E en la casa del enfermo non fable palabras non pertenescientes a la cura. E non presuma a catar a muger de casa del enfermo por vista sandia, njn fable con ella a conseio sinon por prouecho de la cura". Lanfranco de Milán, Chirurgia Mayor, editado por Herrera, María Teresa y María Estela González de Fauve, Textos y concordancias... op. cit., fol. 3v. El énfasis es mío. El término "sandia" como adjetivo significa necio o simple. Cfr. Herrera, María Teresa (ed.), Diccionario Español de Textos Médicos Antiguos, Madrid, Arco, 1996, s. v. "sandia". Sobre el desarrollo de la "etiqueta médica", García Ballester, Luis, "Ethical Problems in the Early Relationships between Doctors and Patients in Fourteenth Century Spain: On Christian and Jews Practitioners", en Kottek, Samuel S. y Luis García Ballester (eds.), Medicine and Medical Ethics in Medieval and Early Modern Spain. An Intercultural Approach, Jerusalén, The Magnes Press, 1996, pp. 11-32, esp. p. 18.

22 "Ad id autem quod contra hoc objicitur, videtur esse dicendum quod differt applicare manum, ut medicantem, et polluentem. Manus enim applicata ut polluens, inducit mollitem vel sodomiam: sed manus medicans non inducit: sicut etiam dicimus in mulieribus quibus descendit matrix extra os vulvae: praecipitur enim ut digitis reponant eam, et tamen non dicimus manus illas polluere eas vel corrumpere, sed potius medicari eis". El énfasis es mío. Magno, Alberto, Super IV sententiarum, París, Borgnet, 1894, Lib. IV, art. IV, p. 332b.

${ }^{23}$ Mientras Saliceto afirmó que el cirujano debía introducir los dedos en el ano, Chauliac aconsejó hacerlo en la vagina porque esta se sitúa entre el ano y la vejiga. Cfr. De Saliceto, Guglielmus, Summa conservationis et curationis; Chirurgia, Venecia, Marinus Saracenus, 1490, cuaderno V, fol. 4v, col. A; de Chauliac, Guy, Tratado de Cirugía, editado por Herrera, María Teresa y María Estela González de Fauve, Textos y concordancias... op. cit., fol. 156 r.
} 
obras posteriores al XIII omitieron el tratamiento de la partera ${ }^{24}$, pero la mayoría de los tratados bajomedievales asumieron la efectividad terapéutica de la friega venérea, e identificaron siempre como obstetrix o partera a la mujer que debía ejecutarlo ${ }^{25}$. En definitiva, a partir del siglo XIII tocar los genitales femeninos no fue un problema para los hombres, pero se inhibieron cuando la técnica se relacionó con el placer sexual y delegaron esta tarea en las mujeres. A pesar de que la medicina académica lo considerara un procedimiento curativo, la reputación de las parteras se ponía en entredicho, un prestigio indispensable en los juicios de separación matrimonial.

\section{La clausio matricis y la dudosa inspección honorable}

La medicina antigua no describió el himen, pero consideró patológica la oclusión del sexo femenino que impedía que un hombre tuviera acceso carnal a su esposa. Hoy en día se estima que la incidencia del himen imperforado es del 0,1\% y, quizá por ser casos extraordinarios, los libros más influyentes estudiaron esta patología. Que el marido afirmara que era incapaz de penetrar a su esposa demostraba el diagnóstico y, probablemente sin conocer la enfermedad de primera mano, los principales médicos de la Antigüedad describieron la amputación de un tejido que podía crecer cerca de los labios vaginales, en la parte intermedia o junto al cérvix. El lugar y la dureza del tegumento impedían la menstruación, el coito y la concepción si crecía en el exterior de la vulva; si se desarrollaba en medio de la vagina la mujer solo podía menstruar; pero si se formaba en el interior ni menstruaría ni concebiría, aunque podía mantener relaciones sexuales $^{26}$. Los libros de medicina antigua más importantes describieron la intervención sin mencionar la necesidad de que una obstetrix ejecutara la cirugía, aunque en la Edad Media hubo dos posturas sobre quién debía reconocer a la paciente y extirpar el tejido: si en la Alta Edad

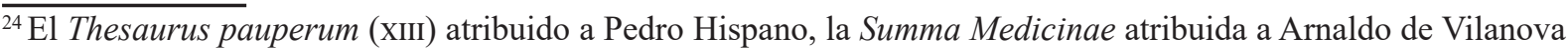
o el Compendio de la humana salud de Johannes de Ketham (XIV) son algunos ejemplos. La traducción castellana del Thesaurus aparece bajo la autoría de Gilbertus Anglicus. Libro de recetas, editado por Herrera, María Teresa y María Estela González de Fauve, Textos y concordancias... op. cit., fols. 36r-38r. Sobre la equivocación en la atribución del texto $c f r$. Moral de Calatrava, Paloma, "Frígidos y melaficiados. Los remedios contra la impotencia en la Edad Media", en Asclepio. Revista de Historia de la Medicina y de la Ciencia, vol. 64, 2 (2012), pp. 353372, esp. p. 362. Otros textos en los que no aparece la obstetrix son de la Rosa Cubo, Cristina, Summa Medicinae (Mdd. Esc. M.II.17). Estudio y edición crítica, tesis doctoral, Valladolid, Universidad de Valladolid, 2000; Ketham, Johannes, Compendio de la humana salud, editado por Herrera, María Teresa y María Estela González de Fauve, Textos y concordancias... op. cit., fol. 40v.

${ }^{25}$ La única excepción en este sentido está en la Summa conservationis et curationis que Guillermo de Saliceto elaboró en 1285 cuando afirmó "et obstetrix vel mulier docta in hoc iponere digitum inunctum cum oleo de spica vel de lilio in os vulue et tricare fortiter illum locum cum digito", de modo que para el cirujano italiano una partera o cualquier otra mujer sabia podía ejecutar el masaje. Cfr. De Saliceto, Guglielmus, Summa conservationis... op. cit., cuaderno I, fol. 3a. Helen Rodnite Lemay afirmó que Guillermo de Saliceto evitó recomendar el masaje de la partera para adaptarse a la moral cristiana. Cfr. Lemay, Helen R., "William of Saliceto on Human Sexuality", en Viator, 12 (1981), pp. 165-181, esp. p. 178.

${ }^{26}$ Muscio. Gynaecia... op. cit., p. 204.
} 
Media aparecían las parteras inspeccionando y operando, a partir del XII médicos y cirujanos se consideraron parte legítima en la intervención.

Muscio (VI), Albucasis (x) y Constantino el Africano (XI) respaldaron la presencia femenina diagnosticando y extirpando el tejido a la paciente. Según Muscio, la partera usaría la vista cuando la membrana creciera en la parte externa, el tacto cuando apareciera en medio de la vagina y el espéculo si estaba en el orificio interno de la matriz. Además de determinar el grado de incapacidad para cumplir con las funciones propias de las mujeres - menstruar, concebir y yacer-, la obstetrix rasgaría el tejido fino con un bisturí, pero si la paciente tenía una membrana carnosa y dura debía extirparla cuidadosamente y aplicar ungüentos cicatrizantes ${ }^{27}$. Si Muscio tradujo a Sorano, Albucasis utilizó como fuente principal al médico bizantino Pablo de Egina, y el cordobés apoyó que las mujeres ejecutaran la cirugía si la afectada era pudorosa o si la incisión debía realizarse en una zona profunda, pero mantuvo que el cirujano podía operar con el consentimiento de la paciente ${ }^{28}$. Constantino el Africano también utilizó la obra del egineta como fuente fundamental para su Cirugía, pero para él era evidente que la obstetrix debía inspeccionar y cortar el tejido, y no contempló la posibilidad de que lo hiciera un hombre ${ }^{29}$.

Por lo tanto, hasta el siglo XI las fuentes fueron relativamente homogéneas al identificar a la obstetrix como autora de la intervención, porque solo Albucasis defendió la posibilidad de que un hombre operara. Pero en el XII se inició el cambio ideológico sobre la práctica médica masculina en los genitales femeninos, y los médicos comenzaron a ocupar el tradicional espacio femenino; una tendencia que también se observa en la sofocación uterina. El salernitano Sancto Paulo (XI) fue el primero en sustituir el vocablo partera por el término genérico de mulier ${ }^{30}$, pero la traducción latina del Canon de Avicena (XIII) afirmaba que, con la ayuda del espéculo, "medicus administret scissione siphac et incisione carnis" (el médico separe el tejido y corte la carne $)^{31}$. Desde entonces, y sin modificar el modo en el que debía ejecutarse la operación, la medicina académica sustituyó a la obstetrix por el cirujano, aunque en las obras redactadas en romance la partera seguía realizando la cirugía ${ }^{32}$. Es decir, en la Baja Edad Media convivieron dos corrientes y si los tratados médicos escritos en latín para los universitarios defendían que eran los hombres quienes operaban, las obras vernáculas mantenían que el corte lo hacía una mujer.

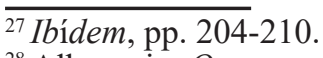

${ }^{28}$ Albucasis, On surgery and Instruments, Berkeley, University of California Press, 1973, p. 458. Albucasis no explicó por qué la profundidad era un criterio que determinaba la participación femenina.

${ }^{29}$ Constantine the African, Chirurgia, Roma, Universitá di Roma, 1960, p. 56.

30 "Apprehenduntur hec omnia patefactis mulieribus ut uisu uideantur et tactu probari possunt. Curentur autem cirurgia". Tomado de Green, Monica, Making Masculine... op. cit., p. 43, n. 37.

${ }^{31}$ Avicenna, Liber Canonis... op. cit., Tract. IIII, Lib. III, fen XXI, fol. 374va. El término siphac suele entenderse como peritoneo, pero Montero Cartelle ya aclaró que podían utilizar el término de forma genérica como membrana. Cfr. Sprumont, Pierre, "Anatomical Terms: towards Development of Terminologies (terminogenesis)", en European Journal of Anatomy, vol. 20, 3 (2016), pp. 249-280, esp. pp. 272-273; Montero Cartelle, Enrique, Tipología de la literatura médica latina: Antigüedad, Edad Media, Renacimiento, Oporto, Brepols, 2010, esp. pp. 117-118. DOI: https://doi.org/10.1484/M.TEMA-EB.5.107179.

${ }^{32}$ Como en el anónimo Tratado de la patología del xv, editado por Herrera, María Teresa y María Nieves Sánchez, Tratado de patología, Madrid, Arco, 1997, pp. 720- 721.
} 
La intervención quirúrgica para tratar la clausio matricis fue infrecuente, pero la Iglesia entendió que la oclusión de la matriz era una condición corporal que no se restringía a un extraño problema médico, sino que consideró que una mujer cerrada era aquella que no podía ser penetrada por su marido. De forma paralela a la reapropiación masculina de una intervención infrecuente, la Iglesia desarrolló mecanismos para anular los matrimonios inconsumados por impotencia y, ya fuera por la falta de vigor masculino o por la estrechez femenina, obligaron a las esposas a pasar un examen físico ante un grupo de mujeres a las que llamaron matronas. El incipiente derecho canónico estimó fundamental un diagnóstico certero de la virginidad femenina porque se trataba de anular un sacramento, y la inspección de la integridad física de la casada fue una de las distintas pruebas que necesitaban para apoyar su decisión ${ }^{33}$. Pero, tanto las acusaciones de las esposas como la exploración de las matronas fueron ampliamente cuestionadas. Agustín de Hipona ya había advertido de que durante la exploración algunas vírgenes podían perder la integridad corporal por accidente, impericia o malicia de la obstetrix ${ }^{34}$. Alberto Magno, por su parte, afirmó que las mujeres podían aparentar ser vírgenes utilizando medicamentos y difundió, así, la sospecha de mentir a todas aquellas que solicitaban la anulación matrimonial por la incapacidad de sus maridos ${ }^{35}$. Tanto el hiponense como el profesor de Colonia mostraron sus dudas, y si el primero desconfiaba de la pericia de las parteras, el segundo dudaba de las mujeres que denunciaban a sus maridos. Por lo tanto, las mujeres en su conjunto estuvieron bajo sospecha; unos recelos eclesiásticos que alcanzaron a las parteras.

El estereotipo de la obstetrix inmoral se condensó en el término vetula para describir a una vieja alcahueta experta en problemas sexuales ${ }^{36}$, y ya Celestino III (1191-1198) dictó que los testigos con mala reputación fueran excluidos de los pleitos matrimoniales. Pero pronto se percataron de que la honestidad era una condición insuficiente, porque su sucesor, Inocencio III (1198-1216), tuvo que decidir qué hacer en un caso que le llegó desde Auxerre ${ }^{37}$. Una mujer fue inspeccionada por un grupo de matronas y encontraron que era incapaz de prestar el débito conyugal y, en consecuencia, se disolvió el matrimonio e ingresó en un monasterio. Pero rompió el voto de castidad porque tuvo una relación sexual ilícita que la "abrió" y la hizo apta para mantener relaciones carnales, de modo que se enfrentaban a un dilema: ¿debía restituirse el primer matrimonio o permanecer enclaustrada como monja? Inocencio III sopesó la solemnidad

\footnotetext{
${ }^{33}$ Moral de Calatrava, Paloma, "La «mujer cerrada»: La impotencia femenina en la Edad Media y el peritaje médico-legal de las parteras", en Dynamis, Acta Hispanica ad Medicinae Scientiarumque Historiam Illustrandam, vol. 33, 2 (2013), pp. 461-483.

34 "Obstetrix uirginis cuiusdam integritatem manu uelut explorans siue maleuolentia siue inscitia siue casu, dum inspicit, perdidit". Augustinus, De Civitate Dei, Turnholti, Brepols, 1955, p. 19.

35 "Sunt tamen quaedam quae medicinis ad hoc competentibus rugosam post multum concubitum faciunt matricem in collo vulvae, et ipsa rugositas effigiat panniculos, et virgines inexpertis apparebunt". Magno, Alberto, De Animalibus, Münster, Aschendorff, 1916, Lib. I, tract., II, cap. 24, p. 164.

${ }^{36}$ Ziolkowski, Jan M., "Obscenity", en Schaus, Margaret (ed.), Women and Gender in Medieval Europe. An Encyclopedia, Nueva York, Routledge, 2006, pp. 618-619; Moral de Calatrava, Paloma, "Frígidos y Maleficiados..." op. cit., p. 355; Lemay, Helen R., "Anthonius Guainerius and Medieval Gynecology”, en Kirshner, Julius y Suzanne Fonay Wemple, Women of the Medieval World, Oxford, Blackwell, 1985, pp. 317-336, esp. p. 326-327.

${ }^{37}$ En las Decretales aparece como una consulta del "Altissodorensi Episcopo", que fue el nombre latino de Auxerre. Cfr. Diccionario Geográfico Universal, Barcelona, José Torner, 1831, p. 588.
} 
de los votos monacales y determinó que si eran simples debía volver con su marido, pese a que este tuviera nueva esposa. Aunque las matronas habían afirmado que esa mujer "deerat instrumentum" (carecía de instrumento), el papa siguió calificándolas de próvidas y honestas ${ }^{38}$. Inocencio III culpó a la monja díscola de acusar al marido en falso y engañar a las monjas del monasterio, pero mantuvo el prestigio de las matronas.

Era indudable que para la Iglesia la cualidad moral de esas mujeres era una condición necesaria, pero limitada, porque solo la honradez no las hacía aptas para juzgar el cuerpo femenino. Por ello, el siguiente en la silla de San Pedro, Honorio III (1216-1227), perfeccionó el procedimiento y endureció los requisitos de separación: desde entonces los tribunales debían asegurarse de los conocimientos de esas mujeres. Para ofrecer estas soluciones, sin embargo, esperó a que se plantearan los siguientes casos. Tras estar casada durante ocho años, una mujer solicitó la separación de su esposo porque él no era capaz de cumplir con el débito conyugal. La virginidad de la esposa fue confirmada por "matronis bonae opiniones, fide dignis ac expertis in opere nuptiali" (matronas de buena reputación, fidedignas y expertas en tareas matrimoniales) ${ }^{39}$. La inspección era el último recurso, porque el nuevo papa exigió que, antes de que la examinaran físicamente, la pareja conviviera durante tres años seguidos, que hicieran penitencia de sus pecados para eliminar la posible interferencia diabólica, que siete parientes confirmaran que el matrimonio no había sido consumado y, además, que el párroco buscara entre las vecinas si alguna de ellas había mantenido relaciones con el marido supuestamente impotente. El segundo caso también implicaba a una monja. Un matrimonio sienés fue separado porque no había sido consumado y el tribunal eclesiástico dictaminó que la mujer ingresara en un monasterio, pero el hombre reclamó que le fuera devuelta su esposa. Ella se negó a volver con él y alegó que había sido declarada virgen tras la inspección de un grupo de mujeres, a lo que el marido replicó que no solo tenían mala fama, sino que no sabían. El tribunal consultó al papa, quien respondió lo siguiente:

"Causam matritmonii, quae inter V. Iuvenera et G. puellam Senonensem, quae se virginem et monacham profitetur, noscitur agilari, quia non ita instructam misisti, frater episcope, ut in ea usque ad calculum sententiae diffinitivae procedere libere valeremus, vobis remitimus plenius instruendam; discretioni vestrae Mandamus, quatenus eandem puellam ponatis interim in illo monasterio auctoritate apostolica, quod intravit, ut ibi secure valeat commorari, donec iudiciali sententia quid agi debeat decernatur, recepturi postmodum, prout iustitia dictaverit, non solum probationes viri, sicut protestatus fuerat, quas inducere voluerit contra mulieres illas, quae ad investigandum signa virginitatis ex parte puellae fuerunt introductae, verum etiam probationes alias hoc negotium contingentes, quas pars utralibet duxerit producendas.

\footnotetext{
${ }^{38}$ Decretalium Collectiones, Graz, Akademische Druck, 1959, pp. 706-707.

${ }^{39}$ Ibídem, pp. 707-708.
} 
Et quia, ut dicit canon, saepe manus fallitur et oculus obstetricum, volumus et mandamus, ut adhuc honestas matronas providas et prudentes deputare curetis ad inquirendum, utrum dieta puella virginitatis privilegio sit munita, causamque nobis sub vestris sigillis instructam plenius remittatis"40.

El papa decidió que la monja/esposa permaneciera en el monasterio hasta que un nuevo grupo de mujeres volviera a explorarla, pero el interés de la respuesta de Honorio III no solo reside en identificar con tres palabras a las mujeres que debían hacer el reconocimiento, sino que también es importante el orden en el que aparecen en la decretal latina: mulieres, obstetrix, matronas. La fama de ignorantes de las primeras explica por qué el pontífice tan solo las reconoció como mulieres, un término que de ningún modo implicaba que tuvieran conocimientos médicos. Después recordó las sospechas de los errores diagnósticos de las obstetrices y, aunque las calificó con un término claramente ligado a la medicina, también dudó del juicio de estas mujeres. Finalmente, aclaró que quienes debían realizar el examen era un grupo de matronas que debían ser decentes, inteligentes y cuidadosas, unas cualidades que la versión castellana tradujo como honestas y sabias. Esto es, el término matrona solo apareció cuando los atributos morales de las mujeres que inspeccionaban el cuerpo femenino eran determinantes, porque la sentencia eclesiástica se basaba en su palabra.

Que las monjas rompieran el voto de castidad y fueran sometidas a una inspección física que realizaban unas mujeres fue una solución antigua. En el siglo III, el obispo Cipriano ofreció esta solución cuando su homónimo Pomponio le preguntó qué hacer con un grupo de monjas que insistían en ser vírgenes a pesar de dormir con hombres consagrados. El prelado de Cartago propuso este procedimiento, pero también receló de la inspección genital que hacían las mujeres utilizando una frase que, en el siglo xIII, terminó por convertirse en una máxima: "manus obstetricum et oculus saepe fallatur" (las manos y los ojos de las parteras a menudo engañan $)^{41}$. En la Edad Media, antes de que Honorio III retomara esta medida, dos importantes personajes del siglo XII se hicieron eco de esta solución, pero si Ivo de Chartres fue más fiel a la intención inicial al tomarlo como solución a la indisciplina eclesiástica femenina ${ }^{42}$, Graciano

\footnotetext{
${ }^{40}$ Friedberg, Aemilius (ed.), Corpus Iuri Canonici, Graz, Akademische Druck y Universidad de Verlagsanstalt, 1959, pp. 706-707 En la versión medieval española aparece lo siguiente: "Uno que auie nombre Guillem demandaua restitution de una manceba que dizien Guillelma de Sena, que dizie que era su muger. Ella respondie que non deuie[n] oyr sobresto, ca ella era uirgen e monia, e esto querie prouar como era uirgen e aduxo a mugeres las cuales la cataron e iuraron que era uirgen. Et contra aquellas mugeres dize aquel Guillem que eran de mala fama e non sabidas en aquel fecho, e esto querie prouar. Onde demandaron los juezes al papa si deuien reçebir estas prueuas las quales aduxieron la una parte e la otra, e tengan el negotio. Manda otrossi que pongan aquella manceba entanamientre en aquel monesterio en el qual entro e more segura miente, fata que sea yudgado por sententia que deua seer fecho; manda otrossi que otras mugeres honestas e sabias que caten si es uirgen, ca dize el decreto [que] la mano e el ojo de las parteras e de las que tal cosa catan muchas uezes son engañadas". Mans Puigarnau, Jaime M., Decretales de Gregorio IX, Barcelona, Universidad de Barcelona, 1939, pp. 61-62. Los énfasis son míos. ${ }^{41}$ Cypriani, Caecili, Opera Omnia, Viena, Geroldi Filium Bibliopolam Academiae, 1871, pp. 474-475.

${ }^{42}$ Ivo Carnotensis, Decretum, p. 573. También disponible en «https://ivo-of-chartres.github.io/decretum/ivodec_7. pdf» [consultado el 23 de septiembre de 2017].
} 
lo incorporó al derecho matrimonial para los casos de las parejas en las que había monjas implicadas ${ }^{43}$. Aunque las obstetrices pudieran explorar la integridad física femenina, la Iglesia debía asegurarse de la honradez de aquellas que actuaban como peritas, y para ello recurrieron al término latino de matrona que oscurecía sus competencias médicas.

Así pues, hasta el siglo xi la literatura médica fue homogénea al afirmar que la obstetrix inspeccionaba los genitales femeninos y operaba a las mujeres cerradas, pero en el XII los médicos sustituyeron este vocablo técnico por el de mulier porque comenzaron a concebirse a sí mismos capacitados para realizar la intervención. En el XIII, la opinión de Avicena fue determinante para que, en los textos médicos escritos en latín, los hombres aparecieran ejecutando una cirugía a las esposas demasiado estrechas para yacer. De forma paralela a la medicina, los hombres de Iglesia utilizaron a las obstetrices para inspeccionar la virginidad de las monjas díscolas, pero recordaron las quejas de los primeros cristianos sobre su mala fama. Por eso, cuando tuvieron que decidir el fututo de una mujer y elegir para ella entre el matrimonio o la vida consagrada, o bien cuando una casada cuestionaba la virilidad del esposo, sustituyeron el término obstetrix por el de matrona.

\section{Esparciendo prejuicios}

Las mujeres que masajeaban el sexo femenino para curar a las enfermas de sofocación fueron sistemáticamente llamadas obstetrix a lo largo de la Edad Media, pero para los tribunales eclesiásticos no era posible aceptar el testimonio de aquellas que realizaban un masaje inmoral porque, finalmente, provocaban el orgasmo femenino. El término matrona fue el resultado de acentuar las cualidades morales de esas mujeres en detrimento de sus competencias médicas, y esas voces reflejaron al tiempo cómo las estereotiparon. De hecho, la medicina también desacreditó a las matronas que testificaban en los juicios por impotentia coeundi para asumir ellos la prerrogativa y poder extender su influencia social. El más prestigioso cirujano europeo de la Edad Media, Guy de Chauliac, terminó en 1363 su Cirugía Magna y si la obstetrix aparece en dos capítulos sobre el parto, la matrona está en el dedicado a las enfermedades de la verga. Chauliac adulteró el procedimiento eclesiástico que seguían para separar a los matrimonios porque afirmó que eran los médicos quienes debían testificar ante el tribunal. Sin embargo, puntualizó que la matrona debía ungir los genitales de pareja con determinados medicamentos

\footnotetext{
${ }^{43}$ Friedberg, Emil, Decretum magistri Gratiani, Graz, Akademische Druck y Universidad de Verlagsanstalt, 1959, pp. $1048-1049$.
} 
y educar sexualmente al marido para que pudiera consumar el matrimonio. A pesar de llamarla matrona y concederle supuestamente cualidades morales, advirtió a los médicos de la frecuencia de sus engaños equiparándolas así a las malas obstetrices, como muestra la versión castellana de 1498:

"Es iuzgado tanbien que si los tales fuessen ayuntados por la fortuna, que sea fecho el diuorcion por iusticia. Mas porque la iusticia acostumbro cometer el examen a los médicos, por tanto se pone aquí el modo de examinar: et es que el medico auida la licencia de la iusticia examine primero la complexión et la composicion de los miembros generatiuos, dende aya matrona en tales cosas acostumbrada: et sea mandado que duerman juntamente por algunos días essa matrona presente con ellos: et de a ellos species: et pimientas: et caliente a ello et vnte con azeites calientes et freguelos cerca del fuego de sarmiento: et mande a ellos fablar en vno et abraçarse. Dende aquello que ouiere visto recuente al medico. E quando el medico es bien enformado ante la iusticia de la verdad puede deponer. Mas guardese que no sea engañado porque muchos engaños en tales cosas se acostumbraron cometerse. Et muy grand peligro es apartar aquellos que dios ayunto: saluo si muy iusta causa lo requiriesse" ${ }^{44}$.

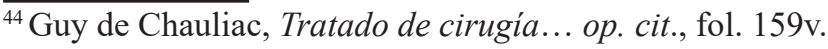

